\title{
LETTERS
}

\section{Belated acknowledgment}

I would like to apologize for an important omission in my editorial of Mar. 29, 2021, on tackling antiracism at CMAJ. ${ }^{1}$ At the end of the piece, I thank people "who have already pointed out structural racism at CMAJ and have patiently taken the time to educate me," but I chose not to name or explicitly acknowledge anyone. In so doing, I did what many white would-be allies do: I made invisible the labour and courage of racialized people and organizations who have worked hard to raise awareness of structural racism and to advocate for change. As has happened many times before, some among them had to take the time to explain this to me. And so, my journey of learning continues. ${ }^{2}$

Dr. Janet Smylie, Dr. OmiSoore Dryden and Dr. Onye Nnorom have spent much time informing my understanding of how a lack of meaningful diversity among editors, statisticians and others who make publication decisions at CMAJ affects both what is submitted to the journal and what CMAJ publishes. Drs. Smylie, Nnorom and Dryden have all emphasized the importance of acknowledging that observed differences in health outcomes are less related to race than to experiences of colonialism and racism. Dr. Dryden suggested hiring an editor with expertise in critical race theory, emphasizing - using an example of an article the CMAJ team chose to publish - that appropriate recognition of the expertise of such an editor would mean actively supporting them to challenge and override the unconscious biases and racism of the existing team in making editorial decisions. Dr. Daren Yin, using a particular example of an article he was invited to peer review, also took the time to explain how poor cultural competence among editors could lead to papers with racist undertones being considered for publication, even under the guise of concern about racism. Dr. Yin also encouraged me, as a white person, to speak out and publicly commit to antiracism, rather than always wait on those who are marginalized to do the advocating.

These individuals, and others who preferred not to be named, deserve credit for their work. I gratefully acknowledge that they have influenced my understanding of racism in the realm of medical publishing and have inspired me to embrace discomfort, read widely on how racism affects health and health care, listen empathetically to lived experiences of racism, continue to educate myself on antiracist policymaking and effect change where I can.

\section{Kirsten L. Patrick MBBCh MSc}

Interim editor-in-chief, Canadian Medical

Association Journal, Ottawa, Ont.

Cite as: CMAJ 2021 May 25;193:E777. doi: $10.1503 / \mathrm{cmaj} .78967$

\section{References}

1. Patrick K. CMAJ and antiracism. CMAJ 2021;193: E453-4.

2. Patrick K. Let statements of solidarity on social media not be the end of allyship [blog]. CMAJ 2020 Jun. 03. Available: cmajblogs.com/let-statements -of-solidarity-on-social-media-not-be-the-end-of -allyship/ (accessed 2021 Apr. 27)

Competing interests: See www.cmaj.ca/site/ misc/cmaj_staff.xhtml.

Content licence: This is an Open Access article distributed in accordance with the terms of the Creative Commons Attribution (CC BY-NC-ND 4.0) licence, which permits use, distribution and reproduction in any medium, provided that the original publication is properly cited, the use is noncommercial (i.e., research or educational use), and no modifications or adaptations are made. See: https://creativecommons.org/ licenses/by-nc-nd/4.0/ 